\title{
SCIENTIFIC THINKING: THE BACKBONE OF MODERN SCIENCE AND TECHNOLOGY EDUCATION
}

\author{
Andris Broks \\ University of Latvia, Latvia
}

Science and Technology Education (STE) along with Artistic and Pragmatic Education today is continuously and fast developing branch of education to satisfy actual needs of modern life. It follows the development of scientific research of real life phenomena and implementation of corresponding results in practice. In other words, changes within our life are closely connected with corresponding changes in our education, because educational activities of any person as well as society in total mean specially organized gaining of life experience (knowledge, values, skills) for life (cognition, consideration, behaviour).

\begin{tabular}{cccc}
\hline $\begin{array}{c}\text { Science and } \\
\text { Technology } \\
\text { Education }\end{array}$ & $\begin{array}{c}\text { Humanitarian sciences and } \\
\text { technologies }\end{array}$ & $\begin{array}{c}\text { Social sciences and } \\
\text { technologies }\end{array}$ & $\begin{array}{c}\text { Nciences and } \\
\text { technologies }\end{array}$ \\
\hline $\begin{array}{c}\text { Knowledge } \\
\text { Values }\end{array}$ & $*$ & $*$ & $*$ \\
Skills & $*$ & $*$ & $*$ \\
\hline
\end{tabular}

The terms "Science" and "Technology" are widely used in our everyday life to demonstrate the principal unity of fundamental scientific research and applied scientific research. When we are using the term "Science and Technology Education", today we need to think about educational scientific research (ESR) including studies of the content and methodology of fundamental as well as applied scientific research.

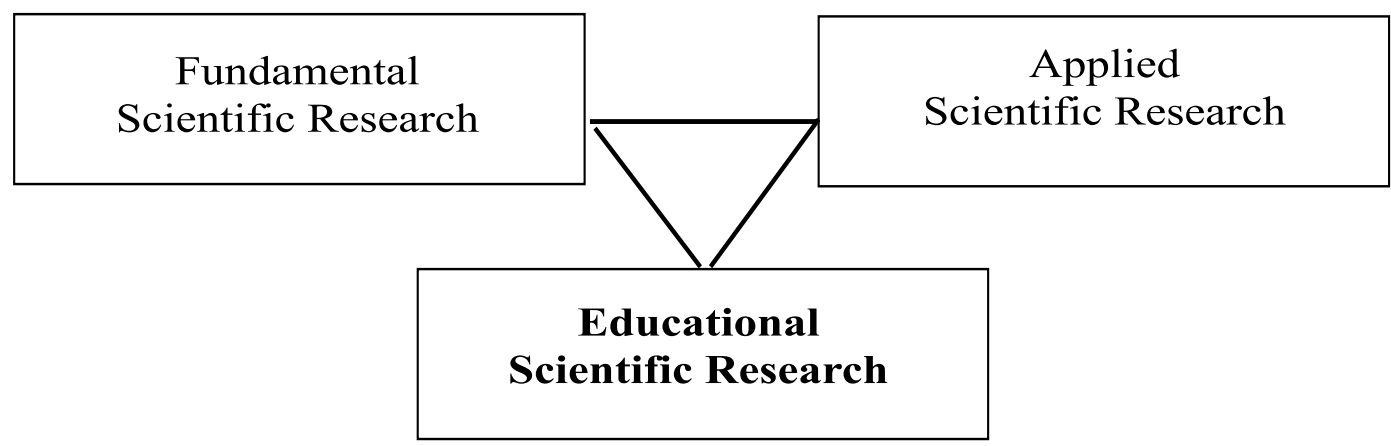

Traditional STE is concentrating on gaining appropriate professional knowledge and skills. Pedagogical process usually is based on memorization of important selected knowledge and learning formal algorithms for corresponding use of them in practice. There is very small attention paid to develop creative activities when gaining new life 
experience for further development of our life activities. Today, when many former human activities are becoming highly automatized, we need less bio robots, but much more creative people working with already gained great amount of knowledge. We need to pay more attention to special studies of the methodology of scientific research - how do we get corresponding knowledge (fundamental science) and use it (applied science) to satisfy our needs. It means that we need to develop serious studies of scientific thinking as a backbone of modern STE. Along with the organization of pedagogical processes as Educational Scientific Research (ESR) we need to study and develop our pupils' and students' scientific thinking in addition to their artistic and pragmatic thinking.

\section{Homo sapiens - it's mind, feelings and will above instincts}

Human's spirit at
its conscious level $\quad \begin{gathered}\text { Mind } \\ \text { (concepts) } \\ \begin{array}{c}\text { Feelings } \\ \text { (images) } \\ \text { Will } \\ \text { (practical actions) }\end{array}\end{gathered}$

I N S T IN C T S

Philosophical and Psychological background for understanding and comprehension of all three basic kinds of thinking is provided by Systems Theory as a general theory of Systems Thinking. According to this fundamental theory, all phenomena are reflected in human consciousness as SYSTEMS, which are integral units made from their interconnected parts and included within surrounding medium, made from other systems. In other words, humans reflect world as a set or network of manifold phenomena by parts (analysis), comparing these parts and connecting them together (synthesis) - building corresponding theories or models of observed phenomena.

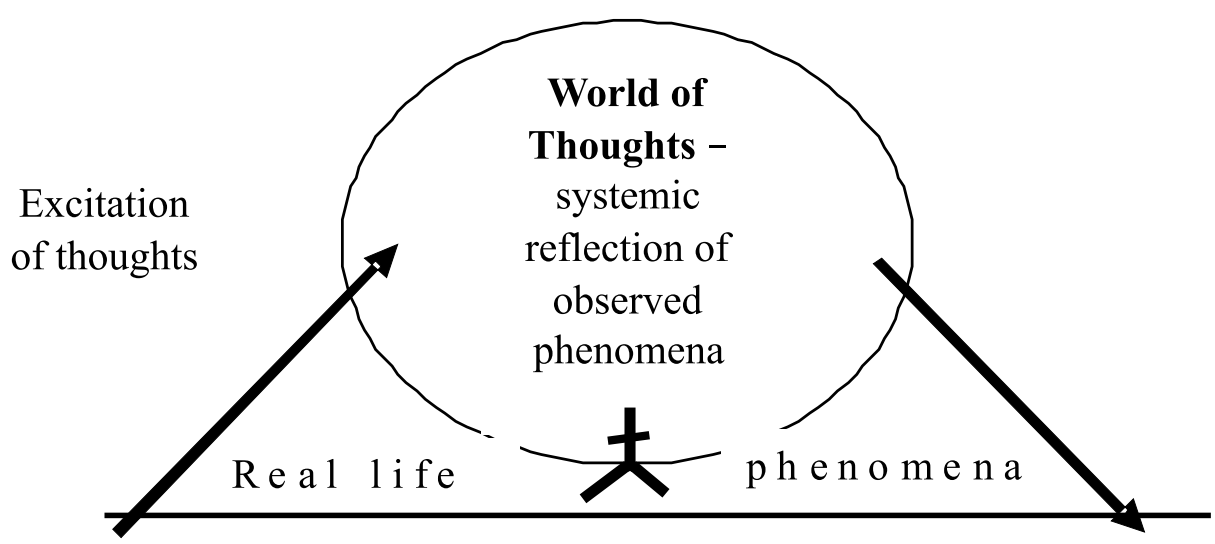

Finally, all human life activities are reflected as systems, that contain three fundamental parts - cognition, consideration and behaviour. The same structure has also all scientific research activities. 
Universal structure of the scientific research of phenomena

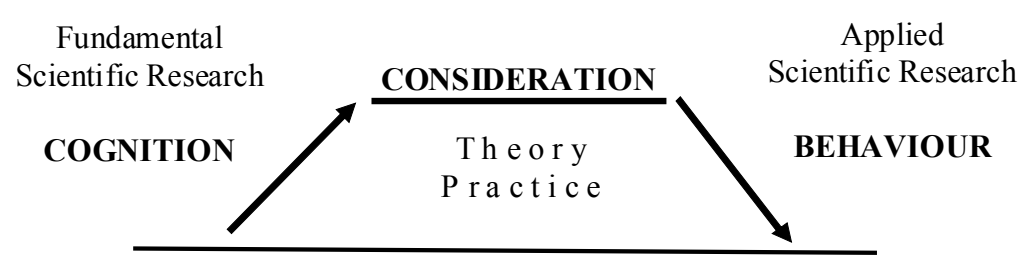

Real life phenomena

Science Education must be s c i e $\mathbf{n} \mathbf{t}$ i f i c - Educational Scientific Research (ESR) within Science and Technology Education (STE) today has to include systemic study of both fundamental and applied scientific research activities, paying special attention to the development of Scientific Thinking. Main features of scientific research as well as of scientific thinking are REALITY of observed phenomena and PRECISION of developed theories / thought structures/models of these phenomena.

Today such development of Science Education with the accent on the development of scientific thinking will be rather exclusive or elitarian because of modern consumer society's life style, that is now spreading all around the world. At the same time we understand, that our societies need not only consumers, but also creative and responsible, clever and honest people to produce things and realize optimal processes we need for our life in future.

Good luck to all who are taking care of modern development of STE today for tomorrow! 